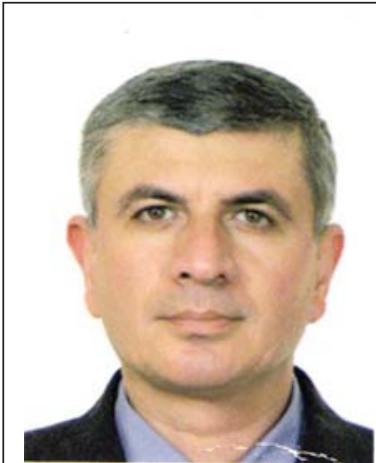

В.Т. Чшиев

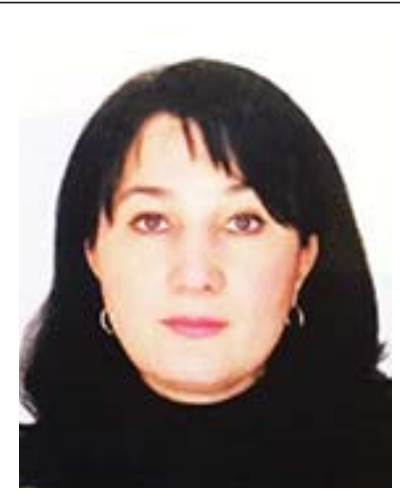

М.Ч. Чшиева

\section{ОБРЯД ВТОРИЧНОГО ЗАХОРОНЕНИЯ В АДАЙДОНСКОМ НЕКРОПОЛЕ КОБАНСКОЙ АРХЕОЛОГИЧЕСКОЙ КУЛЬТУРЫ}

\section{В.Т. Чшиев", М.Ч. Чшиева ${ }^{* *}$}

Аннотация. В статье рассматривается обряд вторичного захоронения, выявленный в ряде ранних погребений Адайдонского могильника кобанской культуры эпохи поздней бронзы. Анализ материалов и особенностей этого обряда свидетельствует о ряде близких элементов в духовной культуре «кобанского» населения высокогорий современной РСО-А и ряде синхронных могильников Центрального Кавказа и Закавказья. Ключевые слова: кобанская культура Кавказа, особенности погребального обряда древнего населения Кавказа.

Обряд вторичного захоронения известен на Кавказе с эпохи бронзы. В первую очередь это памятники эпохи фринала средней - поздней бронзы Западного Закавказья и, вероятно, западной горной части ареала центрального варианта кобанской культуры (высокогорная часть Ирафского района РСО-А). В результате археологических раскопок в Зарамагской котловине [1: 2: 3] этот элемент погребальной обрядности впервые зафиксирован в центральной части Осетии-Алании, в горной зоне Алагирского района, в гробницах Адайдонского некрополя.

Погребальные комплексы кобанской культуры могильника представлены захоронениями большого хронологического диапазона. От времени второй половины 2 тыс. до н. э. вплоть до скифского времени. Разнообразен и погребальный обряд памятника. Это и ингумация с вытянутым на спине или скорченным положением тел и кремация. Ряд ранних захоронений могильника произведены по обряду «очищения костей» или «очищения костяка от плоти» перед вторичным погребением.

Среди погребений, отличающихся хорошей сохранностью и погребального сооружения и содержащегося в нем комплекса, присутствует ряд захоронений, произведенных в прямоугольных гробницах, близких по типу длинному каменному ящику. К числу таких относится гробница № 112 могильника. По длинной оси гробница ориентирована точно по линии север - юг. Покрытие состоит из сланцевых плит и валунов. Продольные стены на высоту 90 и 80 см сложены из крупных валунов. Торцевые - из сланцевых плит, с добавлением валунов. Ширина внутреннего пространства - 60 и 45 см. Длина - 302 см. Пол гробницы тщательно выложен сланцевыми плитами, примыкающими друг к другу (рис. 1).

Несмотря на то, что богатый сопроводительный погребальный инвентарь свидетельствует о

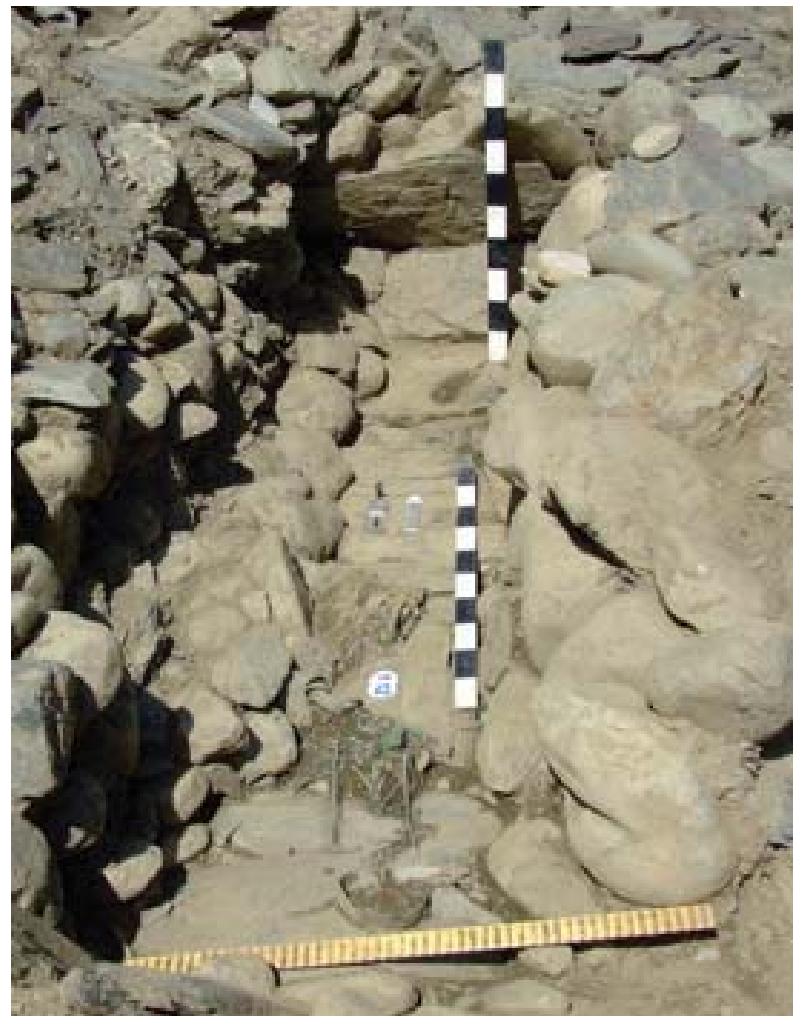

Puc. 1. Адайдонский некрополь. Гробница № 112. Вид с юга

принадлежности данного захоронения к нерядовым представителям «адайдонских кобанцев», как такового костяка в гробнице не обнаружено. Только на полу, в середине гробницы, с некоторым смещением к ее южной половине, компактно располагались фррагментированные трубчатые кости от ног и рук двух взрослых людей (возможно, и трех). Кости были уложены друг на друга парал-

* Чшиев Владимир Таймуразович - к. и. н., ст. н. с. Центра скифро-аланских исследований ВНЦ PAH (hacht@mail.ru).

** Чшиева Мая Черменовна - к. и. н., доцент кафредры философии и истории ГГАУ (hacht@mail.ru). 
лельно длинной оси погребального сооружения.

Размещение погребального инвентаря создает картину раскладывания предметов по контуру (схеме), имитирующему нахождение верхней части человеческого тела в вытянутом на спине положении, с руками, вытянутыми вдоль тела. У северной торцевой стены гробницы на полу была уложена бронзовая диадема с несомкнутыми, несколько зауженными концами и отверстиями в них. Южнее, в области «груди», находились стержневидные бронзовые булавки нескольких типов, цилиндрические витые пронизи, сердоликовые бусы и другие украшения. Еще далее к югу, у западной и восточной стен, на условные «запястья» были уложены 4 браслета, по два вместе. У западной стены, рядом с браслетами, у условной «правой руки», располагалась вотивная бронзовая булава с четырьмя выступами. Еще одна такая булава находилась отдельно в середине погребения. Далее к югу, как отмечено выше, компактно располагалась группа трубчатых костей.

Южная часть в точности, зеркально повторяет расположение инвентаря северной половины гробницы, с тем отличием, что булавки здесь других типов, присутствуют привески в виде топора-секиры, и у самых костей и отчасти под ними находились два бронзовых цельнолитых кинжала и два копья с раскрытой втулкой из этого же металла. Примечательно, что две массивные бронзовые стержневидные булавки были уложены здесь строго параллельно друг другу (рис. 2-3).

Анализ погребального обряда данной гробницы свидетельствует, что она использовалась для неоднократных захоронений, во всяком случае, не менее двух. На наш взгляд, в случае с погребением № 112 и рядом других данного памятника мы наблюдаем захоронение, где присутствует обряд «освобождения костей от плоти». Очищенные от плоти кости (более точно - часть костей) первого захоронения, которому отводилась южная половина гробницы (так как в этой части были зафиксированы предметы вооружения, то, возможно, они принадлежали мужчине), были размещены в середине погребального сооружения, с некоторым смещением к югу. Вокруг них и далее к югу, вплоть до южной торцевой стены, аккуратно выложен сопроводительный погребальный инвентарь. При втором захоронении кости второго костяка были уложены поверх костей первого, а сопутствующие предметы аналогично размещены в северной части гробницы.

Инвентарь гробницы - пластинчатые и литые браслеты овальной фрормы; крупные булавки с пятью выступами; привески в виде топора-секиры; булавки с крупным дисковидным навершием; цельнолитой кинжал; грушевидные бронзовые навершия булав с 4 круглыми выступами; диадемы; булавка с навершием, украшенным фригуркой птицы; булавки с конусовидной головкой; булавки с 5 выступами, один из которых клиновидный - аналогичен кавказским археологическим материалам второй половины 2 тыс. до н. э. из Кумбулта (В. Рутхи), Стырфаза, Тли, Нули, Квасатали, Цоиси и др. [4, с. 470, табл. XLVIII, $12 ; 5$, с. 10 , рис. $7,2-6$; с. 30 , рис. 28,16 ; с. 39 ,

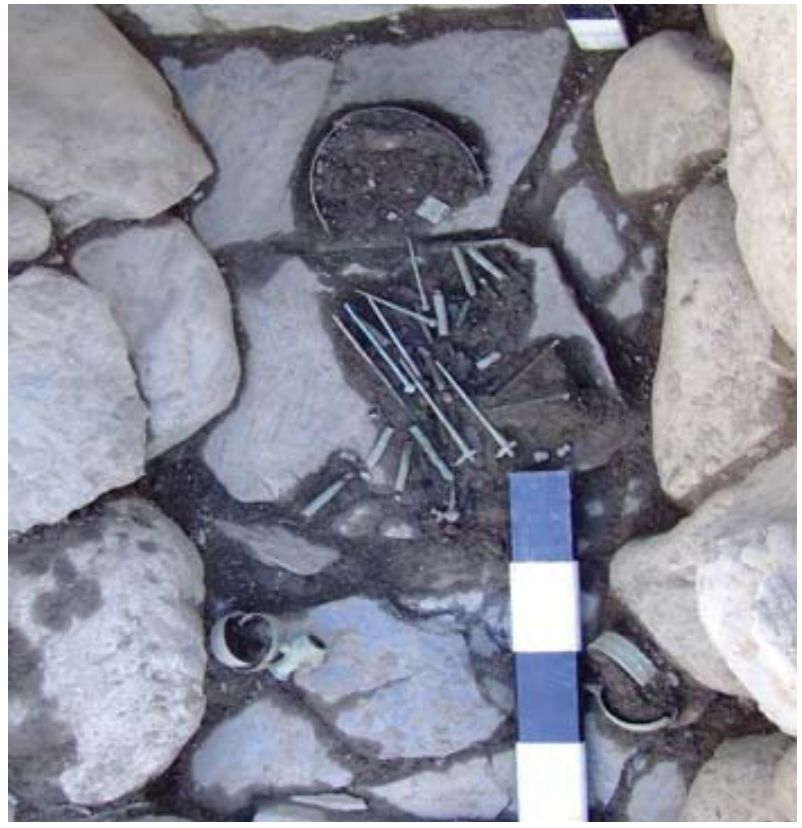

Puc. 2. Адайдонский некрополь. Гробница № 112. Северный торец. Вид сверху. Сопроводительный инвентарь

рис. 40 , 8; с. 52 , рис. $51,1-3$; с. 57 , рис. $54 ; 6$, с. 162 , илл. 23, с. 163 , илл. 24 , с. 166 , илл. $27,1-11$ с. 170 , илл. 31; 7, табл. XVIII, 1; табл. VII, 1; 8, с. 91, рис. 34, $55,60-63$; 9, с. 76 , табл. 3, 51-53, 54-55, 57-58, с. 77, табл. 4, 80; 10, с. 31, рис. 9, 1-2; 11, Taf. 27, 9; Taf. 64, 5; Taf. 76, 9-10; Taf. 78, 8; Taf. 86, 7]. Отметим, что территориально наиболее близкая параллель вышеописанному обряду известна нам в могильниках западной части Колхидской низменности, где также имеются и коллективные захоронения, сочетающие обряд вторичного захоронения костей [12, c. 82-85]. Также в обряде одного из этих колхидских могильников эпохи поздней бронзы раннего железа

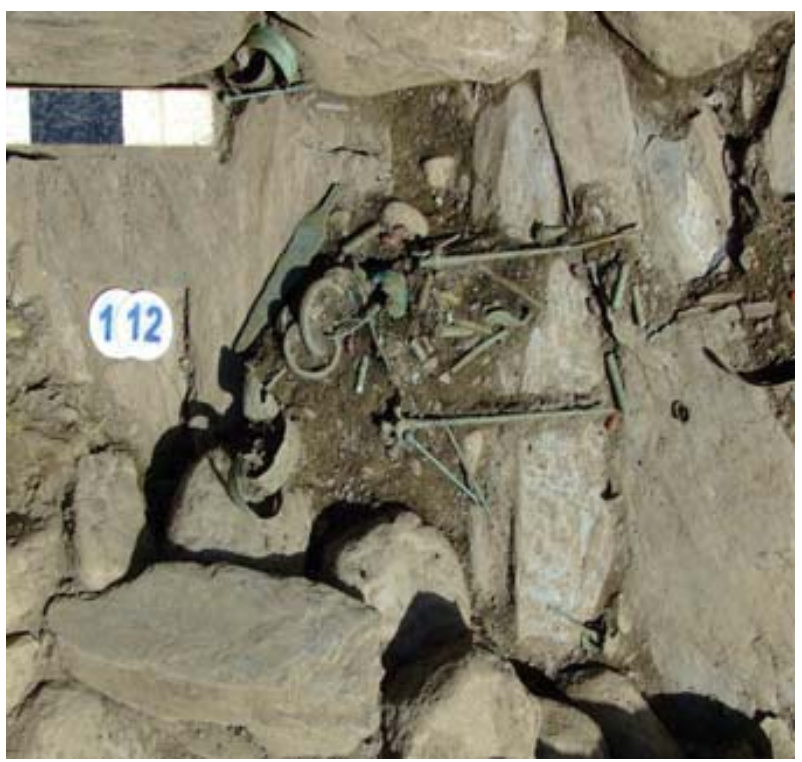

Puc. 3. Адайдонский некрополь. Гробница № 112 Южная часть. Сопроводительный инвентарь 
- Эргетаl - зафиксирован обычай раскладывания инвентаря в гробнице «в определенном порядке и одномоментно», недалеко от отдельно сложенных вторично захороненных костей [13, 2011, с. 96].

Каким способом кости очищались от плоти перед захоронением в гробнице № 112 и ряде других погребений Адайдонского могильника, пока неясно. Это могло быть и вторичное захоронение после пребывания тела какое-то время в грунте и способ «выставления тел» стервятникам для освобождения от плоти, близкий практике древнеиранских «башен молчания» - дахм. Во всяком случае, высокогорье Алагирского ущелья, где и расположен Адайдонский могильник, и сегодня населяют многие виды орлов и стервятников (беркут, могильник, бородач-ягнятник, стервятник, черный гриф, белоголовый сип) $[14$, c. 162, 165-168]. Вероятно, в древности, при наличии более обширной для них кормовой базы, их количество было больше. Возможно, «очищение» от плоти происходило и каким-либо третьим способом. Античные авторы применительно к погребальным обычаям древнего населения Кавказа описывают обычай «воздушного» погребения тел. В частности, в «Походе аргонавтов» Аполлония Родосского (втор. пол III в. до н. э.) сообщается: «...на холме... росло рядами множество ракит и ив, на верхушках которых висели привязанные веревками трупы: и теперь еще считается у колхов святотатством предавать огню трупы умерших мужчин; нельзя даже зарывать их в землю и насыпать сверху могильные холмы: их завертывают в невыдубленные бычачьи шкуры и вешают на деревьях вдали от города» [15, с. 197]. Николай Дамасский (І в. до н. э. - І в. н. э.) отмечает: «42. Колхи покойников не погребают, а вешают на деревьях» [15, с. 235]. Похожий обряд захоронения отмечался на Западном Кавказе еще в 17 в. Эвлия Челеби сообщает: «Примечательно, что [люди] этого племени абаза трупы своих беев чаще всего кладут в деревянную колоду, как в сундук. Прикрепив ее к вершине высокого дерева между двумя ветвями, они оставляют ее там, проделав отверстие у изголовья» [16, с. 38].

Возможно, и здесь мы имеем дело с обрядом вторичного захоронения, когда после очищения костей от плоти в удаленном от мест проживания древнего населения месте («первичное - воздушное погребение») они потом тем или иным образом уже окончательно захоранивались в некрополях.

Таким образом, обряд вторичного захоронения погребенных, известный на примере ряда кавказских некрополей эпохи бронзы, впервые зафиксирован в кругу высокогорных памятников кобанской культуры центральной части РСО-А. Это свидетельствует об определенной близости погребальных обрядов Адайдонского некрополя и отмеченных выше могильников Закавказья.

\section{ЛИТЕРАТУРА}

1. Чииев Х.T. Раскопки Адайдонского могильника кобан ской культуры в 2006-2007 г2.: Предварительные итоги исследования // Отражение цивилизационных процессов в археологических культурах Северного Кавказа и сопредельных территорий. (Юбилейные XXV "Крупновские чтения» по археологии Северного Кавказа). Тезисы докладов / Отв ред. А.А. Туаллагов. - Владикавказ: Изд-во СОИГСИ, 2008. C. $376-380$.

2. Чииев Х.Т. Традиции и инновации в археологии Кавказа (по материалам кобанской археологической культуры) // Проблемы всеобщей истории и политологии / Отв. ред. Б.Г. Койбаев. - Владикавказ: Издательство Северо-Осетинского государственного университета им. К.Л. Хета гурова, 2009. С. 126-134.

3. Чшиев X.T. Эпоха поздней бронзы - раннего железа Сeверной Осетии. Кобанская культура // История Осетии / Отв. ред. С.А. Айларова, А.Г. Кучиев. - Владикавказ: Издательство СОИГСИ им. В. И. Абаева, 2012. Т. 1. С. 53-88.

4. Крупнов Е.И. Древняя история Северного Кавказа. - М.: Изд-во АН СССР, 1960. 520 с.

5. Техов Б.В. Центральный Кавказ в XVI-X вв. до н.э. - М.: Наука, 1977. 238 c.

6. Техов Б.В. Новый памятник эпохи поздней бронзы в Южной Осетии (стырфразские кромлехи). - Владикавказ Цхинвал: Изд - во ВНЦ РАН, 2000. 240 с.

7. Куфтин Б.А. Материалы к археологии Колхиды. - Тбилиси: Изд-во АН ГССР, 1949. 359 c.

8. Козенкова В.И. Культурно-исторические процессы на Северном Кавказе в эпоху поздней бронзы и в раннем железном веке (Узловые проблемы происхождения и развития кобанской культуры). - М.: ИА РАН, 1996. 162 с.

9. Абесадзе Ц.Н. К истории медно-бронзовой металлургии триалетской культуры // Реставрация, консервация, технология музейных экспонатов. Т. 1.: «МЕЦНИЕРЕБА». - Тбилиси, 1974. С. 62-65.

10. Кореневский С.Н. Втульчатые топоры - оружие ближнего боя эпохи средней бронзы Северного Кавказа // Кавказ и Средняя Азия в древности и средневековье. - М.: Наука, 1981. С. $20-41$.

11. Motzenbäcker I. Taf 27, 9; Taf 64, 5; Taf 76, 9 - 10; Taf 78, 8; Taf. 86, 7

12. Папушвили $\boldsymbol{P}$. $К$ вопросу об абсолютной хронологии Колхиды эпохи поздней бронзы - раннего железа // Вопросы древней и средневековой археологии Кавказа / Отв. ред. Х.М. Мамаев. - Грозный-Москва: Инст. археологии РАН; инст. гуманитарных исслед. АН ЧР, 2011. С. 82-94.

13. Скаков А.Ю. Погребальные ямы Колхиды // Вопрось древней и средневековой археологии Кавказа / Отв. ред. Х.М.Мамаев. - Грозный - Москва: Инст. археологии РАН; инст. гуманитарных исслед. АН ЧР, 2011. С. 95-113.

14. Красная книга РСО-А. Красная книга РСО-Алания // Muнистерство охраны окружающей среды РСО-А / Отв. ред. А.Л. Комжа, А.Д. Липкович, К.П. Попов: "Проект - Пресс». - Владикавказ, 1999. 248 с.

15. Латышев В.В. Известия древних писателей о Скифии и Кавказе // Приложение к журналу «Петербургский Археологический вестник. Вып. 3 (XXI) и 4 (XXII): Фарн. - СанктПетербург, 1993. 352 с.

16. Челеби Эвлия. Книга путешествия (Сейахатнаме): Наука. - Москва, 1983. 249 с. 


\title{
THE RITE OF SECONDARY BURIAL AT ADAIDON NECROPOLIS OF KOBAN ARCHAEOLOGICAL CULTURE
}

\author{
V. T. Chshiyev*, M. Ch.Chshiyeva**
}

${ }^{*}$ Chshiyev Vladimir Taimurazovich, Ph. D., Senior Researcher, Vladikavkaz Scientific Center, Russian Academy of Sciences (hacht@mail.ru)

${ }^{* *}$ Chshieva May Cermanova, Ph. D., associate Professor of philosophy and history, Gorsky state agrarian University

Abstract. The article discusses the rite of secondary burial, discovered in a number of early burials in Adaidon burial ground of the Koban culture that belongs to the late bronze age. The analysis of the materials and features of this rite indicates certain similar elements in the spiritual culture of "Koban» population located in the highlands of the present-day North Ossetia-Alania with some burial grounds of the Central Caucasus and Transcaucasia.

Keywords: Koban culture of the Caucasus, the peculiarities of the funeral rite of the ancient population of the Caucasus.

\section{REFERENCES}

1. CHshiev H.T. Raskopki Adajdonskogo mogil'nika kobanskoj kul'tury v 2006-2007 gg.: Predvaritel'nye itogi issledovaniya // Otrazhenie civilizacionnyh processov v arheologicheskih kul'turah Severnogo Kavkaza i sopredel'nyh territorij. (YUbilejnye XXV "Krupnovskie chteniya» po arheologii Severnogo Kavkaza). Tezisy dokladov / Otv. red. A.A. Tuallagov. - Vladikavkaz: Izd-vo SOIGSI, 2008. S. 376-380.

2. CHshiev H.T. Tradicii $i$ innovacii $v$ arheologii Kavkaza (po materialam kobanskoj arheologicheskoj kul'tury) // Problemy vseobshchej istorii i politologii / Otv. red. B.G. Kojbaev. - Vladikavkaz: Izdatel'stvo Severo-Osetinskogo gosudarstvennogo universiteta im. K.L. Hetagurova, 2009. S. 126-134.

3. CHshiev H.T. EHpoha pozdnej bronzy - rannego zheleza Severnoj Osetii. Kobanskaya kul'tura // Istoriya Osetii / Otv. red. S. A. Ajlarova, A. G. Kuchiev. - Vladikavkaz: Izdatel'stvo SOIGSI im. V. I. Abaeva, 2012. T. 1. S. $53-88$.

4. Krupnov E.I. Drevnyaya istoriya Severnogo Kavkaza. - M.: Izd-vo AN SSSR, 1960. 520 s.

5. Tekhov B.V. Central'nyj Kavkaz v XVI-X vv. do n.eh. - M.: Nauka, 1977. 238 s.

6. Tekhov B.V. Novyj pamyatnik ehpohi pozdnej bronzy $v$ YUzhnoj Osetii (styrfazskie kromlekhi). Vladikavkaz - Ckhinval: Izd - vo VNC RAN, 2000. $240 \mathrm{~s}$.

7. Kuftin B.A. Materialy k arheologii Kolhidy. - Tbilisi: Izd-vo AN GSSR, 1949. $359 \mathrm{~s}$.

8. Kozenkova V.I. Kul'turno-istoricheskie processy na Severnom Kavkaze v ehpohu pozdnej bronzy $i v$ rannem zheleznom veke (Uzlovye problemy proiskhozhdeniya i razvitiya kobanskoj kul'tury). - M.: IA RAN, 1996. $162 \mathrm{~s}$.

9. Abesadze C.N. K istorii medno-bronzovoj metallurgii trialetskoj kul'tury // Restavraciya, konservaciya, tekhnologiya muzejnyh ehksponatov. T. 1.: «MECNIEREBA». - Tbilisi, 1974. S. 62-65.

10. Korenevskij S.N. Vtul'chatye topory - oruzhie blizhnego boya ehpohi srednej bronzy Severnogo Kavkaza // Kavkaz i Srednyaya Aziya v drevnosti i srednevekov'e. - M.: Nauka, 1981. S. 20-41.

11. Motzenbäcker I. Taf. 27, 9; Taf. 64, 5; Taf. 76, 9-10; Taf. 78, 8; Taf. 86, 7.

12. Papushvili R. K voprosu ob absolyutnoj hronologii Kolhidy ehpohi pozdnej bronzy - rannego zheleza // Voprosy drevnej i srednevekovoj arheologii Kavkaza / Otv. red. H.M. Mamaev. - Groznyj-Moskva: Inst. arheologii RAN; inst. gumanitarnyh issled. AN CHR, 2011. S. 82-94.

13. Skakov A.YU. Pogrebal'nye yamy Kolhidy // Voprosy drevnej i srednevekovoj arheologii Kavkaza / Otv. red. H.M.Mamaev. - Groznyj - Moskva: Inst. arheologii RAN; inst. gumanitarnyh issled. AN CHR, 2011. S. 95-113.

14. Krasnaya kniga RSO-A. Krasnaya kniga RSO-Alaniya // Ministerstvo ohrany okruzhayushchej sredy RSO-A / Otv. red. A.L. Komzha, A.D. Lipkovich, K.P. Popov: «Proekt - Press». - Vladikavkaz, 1999. 248 s. 15. Latyshev V.V. Izvestiya drevnih pisatelej o Skifii $i$ Kavkaze // Prilozhenie k zhurnalu "Peterburgskij Arheologicheskij vestnik. Vyp. 3 (XXI) i 4 (XXII): Farn. - Sankt-Peterburg, 1993. 352 s.

16. CHelebi EHvliya. Kniga puteshestviya (Sejahatname): Nauka. - Moskva, 1983. 249 s.

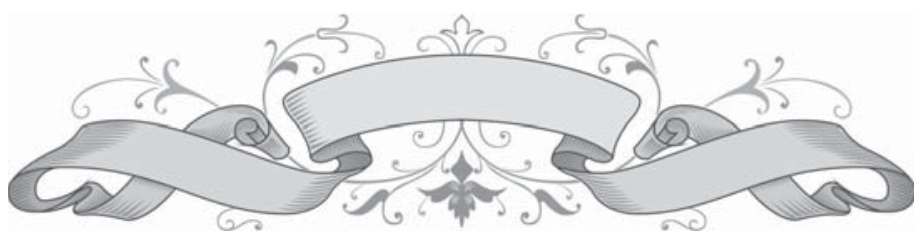

